\title{
Potentiometric Mapping for Wind Turbine Power Plant Installation guilan province in Iran
}

\author{
1*SOBHANI, B; ${ }^{2}$ SAFARIAN, VZ; ${ }^{3}$ KIANIAN, MK \\ ${ }^{I}$ Associate Professo. Department of physical Geography, Climatology, University of Mohaghegh Ardabili, Ardabil, Iran \\ $2^{2 *}$ Ph.D. student. Department of physical geography, Climatology, University of Mohaghegh Ardabili, Ardabil, Iran \\ ${ }^{3}$ Academic Member of Desert Studies Faculty, Semnan University, Iran \\ *Corresponding Author Email: sobhani@uma.ac.ir
}

\begin{abstract}
The use of renewable energy in different parts of the world is increasing in recent years, therefore, understanding the way and how to use these energies is very important. Today, the use of climate and productive energies has attracted more researchers. The purpose of this research is to determine the potential of the wind turbine power plant and mapping in guilan province based on fuzzy logic and AHP. In this research, wind direction and speed data of 4 synoptic stations of guilan province were provided to assess the potential, mapping and determine the establishment of a wind turbine plant in guilan province for sustainable development using fuzzy logic in a statistical period for each synoptic station since its establishment until 2014. In this systemic model, the monthly and seasonal wind speed were scored using the fuzzy method and WindRose Plot and SabaWind software were used to determine the wind direction. Wind speed mapping map was drawn to establish a wind turbine plant with scores obtained for each of the stations using the GIS. The findings of the research show that fuzzy logic method showed a large variation to establish wind turbine power plants using wind speed and wind direction. In total, the Manjil station with the highest windy with the score of 29.29 were ranked first in the construction of wind turbines after obtaining the final rating each of the 4 stations in guilan province to build a high-confidence wind power plant and other stations are the next priorities in the province of Gilan for the establishment of the turbine plant with the scores (Bandar Anzali: 22.79, Astara: 20.37 and Rasht: 17.91). guilan province is suitable for establishing a turbine plant, because of the potential and windy favorable conditions to use it to meet the needs of various energies, including the electricity of the area. Therefore, it is necessary to take steady steps in order to develop this important industry.
\end{abstract}

\section{DOI: https://dx.doi.org/10.4314/jasem.v22i8.36}

Copyright: Copyright $($ C 2018 Sobhani et al. This is an open access article distributed under the Creative Commons Attribution License (CCL), which permits unrestricted use, distribution, and reproduction in any medium, provided the original work is properly cited.

Dates: Received: 25 June 2018; Revised: 23 July: 2018; Accepted: 30 July 2018

Keywords: Wind direction and Speed, Potentiometric, Fuzzy logic, Wind power plant, Statistical analysis.

Energy is one of the most important factors in the progress and development of human communities. Among various turbine- wind generators structures, wind turbine by doubly-fed induction generators are one of the highly accepted structures in the industry. Wind energy is one of the most accessible renewable energies, high precision wind prediction will be effective in developing this energy. The wind turbine is a device that converts wind energy into electrical energy. This is achieved by blades attached to a hub and they turn in response to aerodynamic forces on turbine blades (Pirkandy et al., 2014). Daniel and Ian (2017) explored the impact of climate change on upstream costs of the wind energy and found that generally increased the year-on-year variations in climate. Yan-chonli et al. (2017) developed a CFD analysis tool for marine floating wind turbines and found that CFD modeling makes possible a quantitative analysis of wind turbine flow field, the distribution of pressure along the blades and their effect on the aerodynamics of the wind turbine and the hydrodynamic of the floating structure. Other researchers have also done research on wind turbines, including (Aidin et al., 2010; Lee et al., 2010; Salis and Wikute, 2011; Debnt, 2013; Hadi, 2013; Visacro and Selyurria, 2014; Hey et al., 2014; Delmand, 2014; Filber and Stogljohner, 2014; Chandel et al. , 2014; Imani, 2015; Visacro and Solvia, 2015; Semida and Skelea; 2015; Semida and Skelea; 2016; Ayodel and Oguinjoojib; 2016; Zongpang et al., 2016; Wang et al. , 2016; Reabrairo, 2016). The present study is aimed at investigating and feasibility of mapping for a wind turbine in Gilan province based on AHP to develop the clean and renewable energy use in this region. Therefore, it is possible to carry out detailed studies on climate potentials for establishing the wind power plant in Gilan province and providing the necessary infrastructures in different seasons to provide targeted development fields for the use of clean energy in the study.

\section{MATERIALS AND METHOD}

Characteristics of study area: Gilan province with an area of about $14711 \mathrm{Km}^{2}$ is located between Alborz Mountains and Talesh in north Iran and covers about 0.9 percent total area of the country. This province is limited to the Caspian Sea from the north, from the east to Mazandaran province, from the west and northwest to Ardabil province, and from the south through the Alborz mountain ranges to the provinces of Zanjan and 
Qazvin. Gilan province is between $36^{\circ} 36^{\prime} 3^{\prime \prime}$ to $38^{\circ}$ $27^{\prime} 7^{\prime \prime} \mathrm{N}$ latitude and $48^{\circ} 34^{\prime} 25^{\prime \prime}$ to $50^{\circ} 26^{\prime} 42^{\prime \prime} \mathrm{E}$ of the Greenwich meridian and the White River Tameshk, which runs between Chaboksar and Ramsar, separates it from Mazandaran province. The province of Gilan is part of the north of the country, which includes 5 stations. Figure 1 describes the location of the area and the stations studied and the stations' characteristics and the length of the statistical period of the data used.

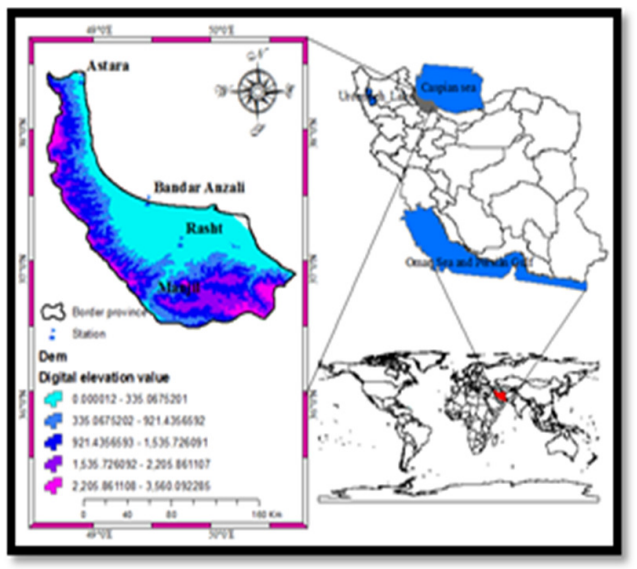

Fig 1: Location of the study area in the world, country, and province

we analyzed the weather statistics of 24-hour synoptic stations in Gilan province with 4 stations with the length of the relevant statistical period to each station since the establishment of the station until 2014 in order to investigate the area and the feasibility of mapping for the establishment of wind turbine in Gilan province based on fuzzy logic and AHP. In this study, wind direction data and wind speed were used. Then, we gave specific weight for the wind climate parameter after obtaining climatic data and normalizing and removing statistical gap using the fuzzy logic method. Then, these data entered the ArcGIS environment with the position and coordinates of the synoptic stations to the digital map of the area and the databases were created and the climatic parameters used in the 9 classes were examined and fuzzy (Table 1).

Table 1: Weights are given for the wind climate parameter to build the wind turbine (source, writers)

\begin{tabular}{cc}
\hline \multicolumn{2}{c}{ Monthly average wind speed $\mathbf{~ m / s}$} \\
\hline 2.5 & Weight \\
$11-13.5$ & 1 \\
$14-16.5$ & 2 \\
$17-19.5$ & 3 \\
$20-22.5$ & 4 \\
$23-25.5$ & 5 \\
$26-28.5$ & 6 \\
$29-31.5$ & 7 \\
$32-34.5$ & 8 \\
$35-37.5$ & 9 \\
\hline
\end{tabular}

Each fuzzy number is a convex fuzzy set: The convexity implies that the membership function is continuous as the piece and its tip is evident in the vicinity of the highest point or distance. Therefore, in order for the value of both indicators to be between 1 and 9 , a different formula is used for each one. So, for the standardization, the relation 1 is used. In this way, the suffering of changes in both indicators will be the same.

$$
\mathrm{x}_{\mathrm{ij}}=\frac{x_{j} \max -x_{j}}{x_{j} \max -x_{j} \min } \quad 1
$$

In this equation, $x_{i j}$ represents the standardized value, $x_{j}$ is the desired index value, $x_{j} \max$ the maximum value in the number series and $x_{j}$ min is the lowest value in the numeric series (Malchowski, 2006). The appropriate layer for each of the parameters was prepared using the IDW interpolation to prepare the scored maps for each of the 12 months for the wind climate parameter, and then a weight for each layer was defined. Each layer was classified into several classes and each class was weighed according to its importance. Technical specifications of the $2.5 \mathrm{MW}$ wind turbines Samen (928 AV) under the license of the Avantis German energy company. total turbine capabilities include 928AV turbines with the output power of $2.5 \mathrm{MW}$ have been built for class IIA wind regime, which has a generator without a medium gearbox and blades with a length of $3 / 45 \mathrm{~m}$. The turbine produces energy at $3 \mathrm{~m} / \mathrm{s}$ and reaches to the maximum energy output at wind speeds above $11 \mathrm{~m} / \mathrm{s}$ ( $2860 \mathrm{~kW}$ at $16 \mathrm{rpm}$ and $95 \%$ efficiency). The energy output conditions are constant up to $25 \mathrm{~m} / \mathrm{s}$ and it automatically stops to prevent damage to the turbine at speeds above $25 \mathrm{~m} / \mathrm{s}$. However, these turbines can withstand against the high pressure of possible storms, as well as the load on blades. Therefore, this turbine is a unique choice for seaside (high wind speed), desert, wet weather, salt and dusts and sandy and near exhaust fumes of diesel engines. The advantage of other turbines is the low hours of out of the orbit, maintenance costs, and the high availability factor and obtained benefits (Safarian Zangir and Zeinali, 2017).

Determination of wind turbine direction: The feature is one of the major variables in wind climatology, the three hours of data harvesting is named Sinop and if the data are taken up to an hour, they will be called "Metal". In the case of precipitation, only the amount of precipitation is important, but in the case of wind, in addition to wind speed, it is important the wind direction, which can represent the cold, humidity and disease etc. The wind has two vectors and two components that are orbital and meridian and the resultant of these two forces is real winds. The orbital winds blow when the earth rotates around itself, and when it does not spin, the meridian winds blow. The observed winds in nature are the result of three forces of pressure gradient, gravity to the center of the earth 
and the force of the Coriolis. Winds are in the directions from 0 to 360 degrees and a speed of 0 to 99 not. WindRose Plot and Saba Wind soft-wares are the soft-ware that can obtain wind directions in the long, annual, monthly, daily and hourly periods. After obtaining the raw data from the meteorological station, the data must be converted to the code 28 in the SabaWind software.

$\mathrm{Knot}^{*} 1.8 / 3.6 \quad 2$

Table 2: Character Data Sample for importing into the Saba Wind environment

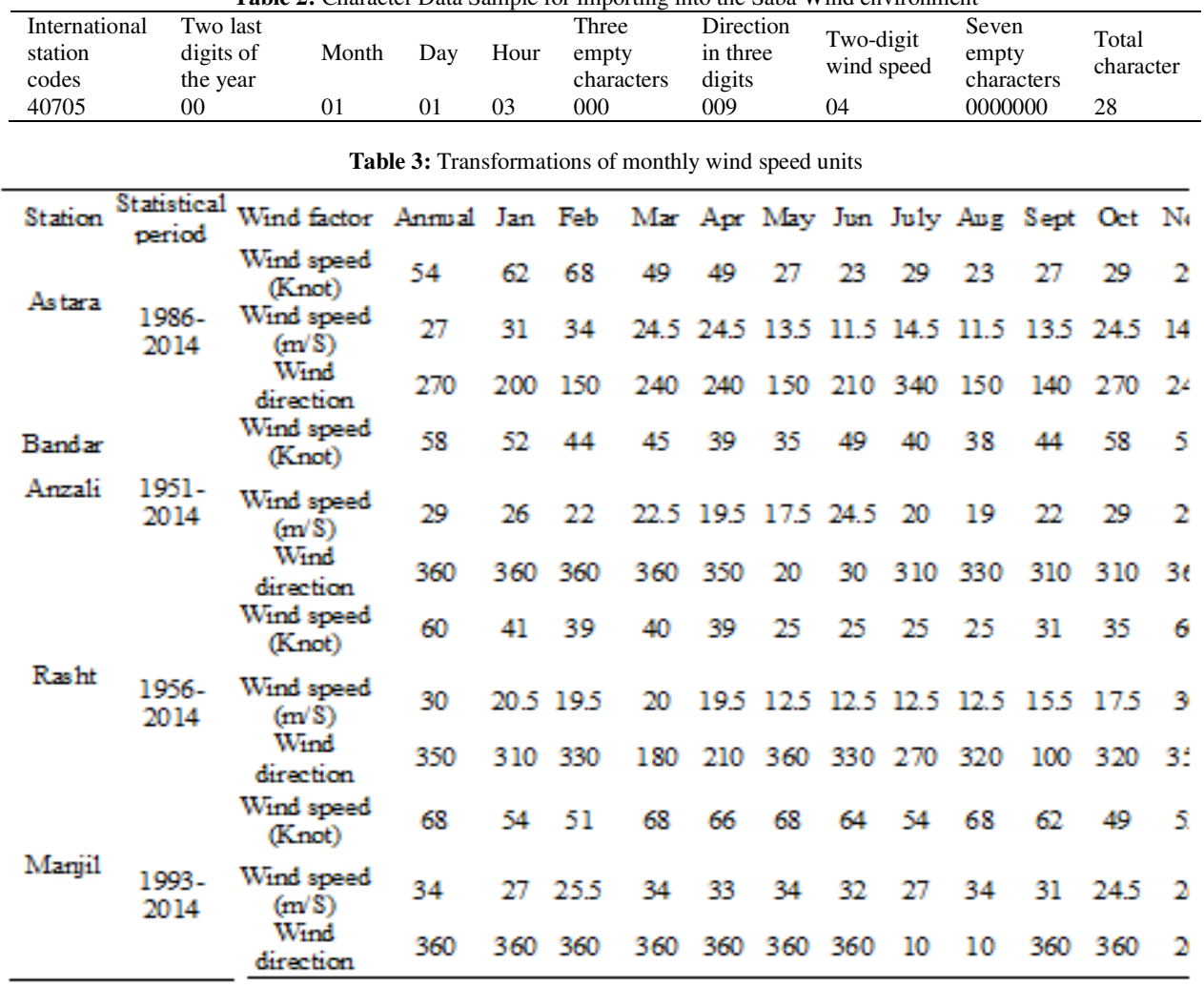

\section{RESULTS AND DISCUSSION}

Then, the score of each month was obtained for 4 stations for the wind direction and wind speed based on the stated equations, and then IDWs interpolation was used to interpolate all stations using the ArcGIS software.

Investigation of lands suitability in Gilan province based on slope to establish the wind turbine: A digital elevation model (DEM) with a scale of 1: 250,000 was used to prepare the slope map of the province. Then, classifications were done according to the favorable and undesirable slope conditions to establish the wind turbines.

Investigation of lands suitability in Gilan province based on the slope to establish the wind turbine:

Table 4: Final scoring on a monthly fuzzy basis

\begin{tabular}{llllllllll}
\hline Months & Astara & Score & $\begin{array}{l}\text { Bandar- } \\
\text { Anzali }\end{array}$ & score & Rasht & Score & Manjil & Score & Final \\
\hline December & 27 & 6 & 22.5 & 4 & 22.5 & 4 & 23.5 & 5 & 19 \\
November & 24.5 & 5 & 29 & 7 & 17.5 & 3 & 24.5 & 5 & 20 \\
October & 14.5 & 2 & 29 & 7 & 30 & 7 & 26 & 6 & 22 \\
September & 13.5 & 1 & 22 & 4 & 15.5 & 2 & 31 & 7 & 14 \\
August & 11.5 & 1 & 19 & 3 & 12.5 & 1 & 34 & 8 & 13 \\
July & 14.5 & 2 & 20 & 4 & 12.5 & 1 & 27 & 6 & 13 \\
June & 11.5 & 1 & 24.5 & 5 & 12.5 & 1 & 32 & 8 & 15 \\
May & 13.5 & 1 & 17.5 & 3 & 12.5 & 1 & 34 & 8 & 13 \\
April & 24.5 & 5 & 19.5 & 3 & 19.5 & 3 & 33 & 8 & 19 \\
March & 24.5 & 5 & 22.5 & 4 & 20 & 4 & 34 & 8 & 21 \\
February & 34 & 9 & 22 & 4 & 19.5 & 3 & 25.5 & 5 & 21 \\
Jamuary & 31 & 8 & 26 & 6 & 20.5 & 4 & 27 & 6 & 24 \\
\hline
\end{tabular}

Table 5: Final Score Seasonally Based on Fuzzy

\begin{tabular}{ccccc}
\multicolumn{6}{c}{ Table 5: Final Score Seasonally Based on Fuzzy } \\
\hline Station & Autumn & winter & spring & summer \\
\hline Astara & 8 & 23 & 11 & 4 \\
Bandar- Anzali & 18 & 14 & 10 & 12 \\
Rasht & 12 & 11 & 8 & 3 \\
Manji & 18 & 16 & 24 & 22 \\
\hline
\end{tabular}

After elevation and slope, the slope direction is considered as an effective physiographic factor in wind energy utilization. In the northern hemisphere, the southern slopes are warmed up earlier than the northern slopes. The most 
heat that the southern slopes get from sunlight is different according to the different seasons and the slope of the earth. A digital elevation model (DEM) was used in the GIS environment to prepare geographic direction maps. According to the map of the slope directions, the slopes south and southeast (SSW) and south and southwest (SSE) have suitable conditions for wind turbine construction.

Interpolation maps based on scores: The windy stations were determined according to the results of the wind unit transformations for the stations as monthly in Table 4, which the Manjil station was ranked first with more than 6 months at speeds of more than $30 \mathrm{~m} / \mathrm{s}$, the mapping map is shown in Figure 2.

Finally, the Manjil station with the highest wind speed with the score of 29.29 was ranked first for the construction of a wind turbine based on the final score obtained for the stations studied in Gilan province, and other stations were allocated the next priorities with scores (Bandar Anzali: 22/79, Astara: 20/37 and Rasht: 17/91) (Figure 4). At Bandar Anzali station, wind turbine direction is at the first priority according to the prevailing wind of the northwest and the second priority the prevailing deputy is in the northern direction (Figure 5- a). In this research, the potential analysis and mapping to establish the wind turbine power plant in Gilan province based on fuzzy logic and AHP with a statistical period of stations were carried out by 2014 and the wind speed and wind direction were studied separately for each of the stations. They were classified into 9 classes, scored and weighted and the percentage of each of them was applied in the final map so that higher value ranges are more important.

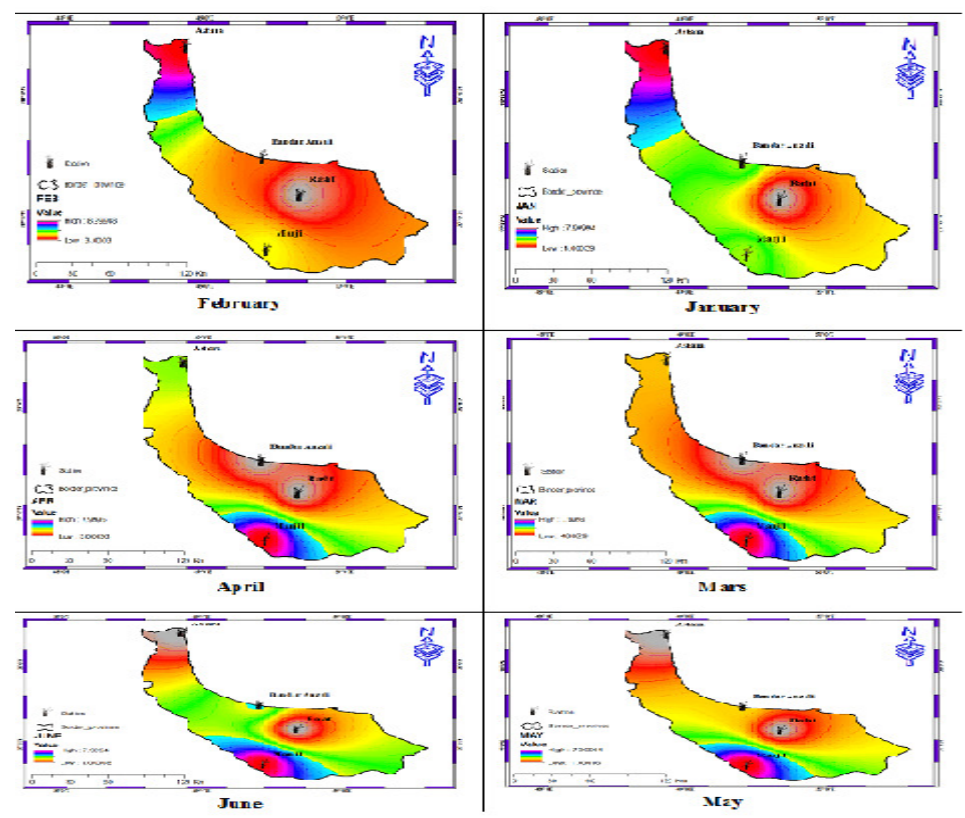

Fig 2: Zoning of the parameters affecting the establishment of a thermal solar power plant

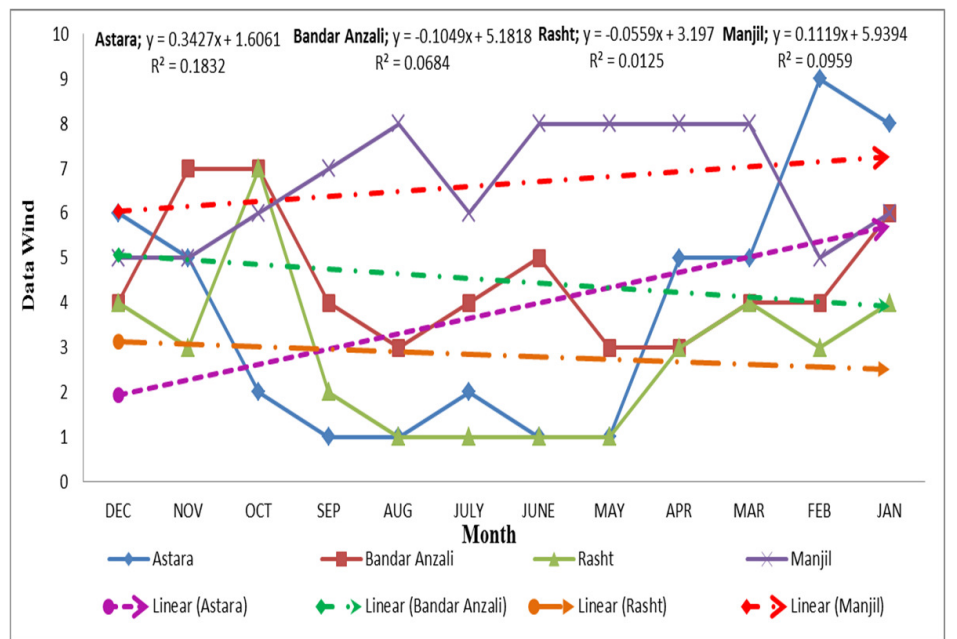

Fig 3: The wind speed distribution diagram of the stations monthly with standard deviation and 


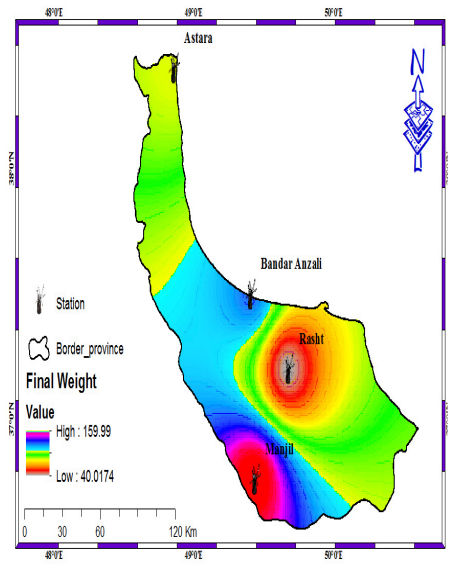

Fig 4: Final mapping of the effective parameters on the establishment of a thermal solar power plant

\section{REFERENCES}

Austin, S; Jerath, S (2017). Effect of soil-foundationstructure interaction on the seismic response of wind turbines, Ain Shams Engineer. J. 8(2): 323-331.

Aydin, NY; kentel, E; Duzgun S (2010). GIS-based environmental assessment of wind energy systems for spatial planning. Renewable and Sustainable Energy Reviews, 14 (4): 364-373.

Ayodele, TR; Ogunjuyigbe, ASO (2016). Wind energy potential of Vesleskarvet and the feasibility of meeting the South African's SANAE IV energy demand. Renewable and Sustainable Energy Reviews, 56(12): 226-234.

Chandel, SS; Ramasamy, P; Murthy, KSR (2014). Wind power potential assessment of 12 locations in the western Himalayan region of India. Renewable and Sustainable Energy Reviews, 39(11): 530-545.

Debnath, P; Gupta, R (2013). Flow physics analysis of three-bucket helical savonius rotor at $90^{\circ}$ twist angle using CFD, Inter. J. Modern Engineer. Res. 3(1): 739-746.
Felber, G; Stoeglehner, G (2014). Onshore wind energy uses in spatial planning a proposal for resolving conflicts with a dynamic safety distance approach, Stoeglehner Energy, Sustainability and Society, 4(1): 1-8.

Felber and Hdidouan, D; Staffell, I (2017). The impact of climate change on the levelised cost of wind energy, Renewable Energy, 101(19): 575-592.

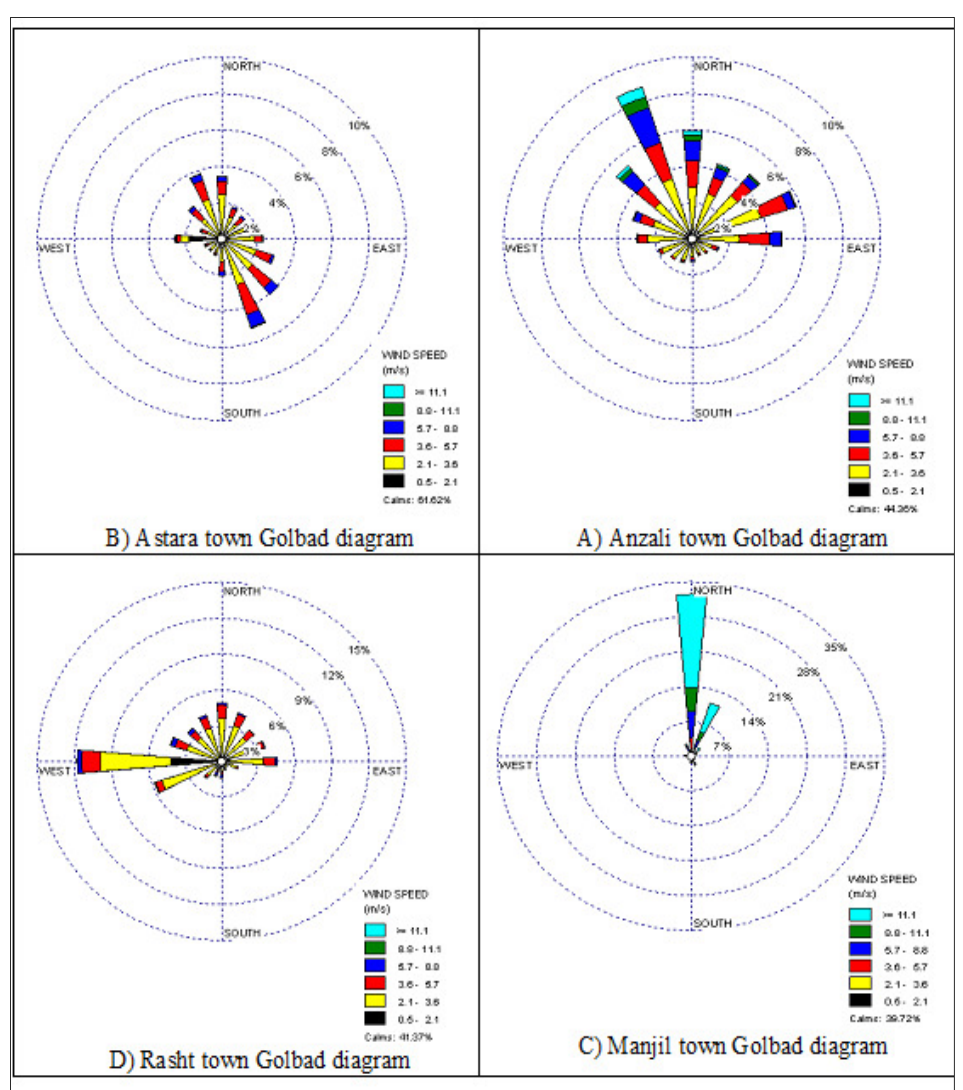

Fig 5: Golbad diagram of the studied stations

Ghalhari, F; Abbas, G; Dadashi-Roodbari, ER; Asadi, M (2016). Potentiometric of wind power plant construction in Isfahan province using the AHP fuzzy method. Iranian J. Energy, 19(3): 67-84.

Hadi, AM (2013). Experimental comparison study for Savonius wind turbine of two and three blades at low wind speed, Intern. J. Modern Engineer. Res. 3(1): 2978-2986,

He, L; Chen-Ching, L; Pitto, A; Cirio, D (2014). Distance Protection of AC Grid with HVDC-Connected Offshore Wind Generators, Power Delivery, IEEE Transactions on, 29 (10): 493-501.

Lee, KH; Jun, SO; Pak, KH; Lee, DH; Lee, KW; Park, JP (2010). Numerical optimization of site selection for offshore wind turbine installation using a genetic algorithm. Current Appl. Phys. 10(4): 302-306.

Liu, Y; Xiao, Q; Incecik, A; Peyrard, Ch; Wanb, D (2017). Establishing a fully coupled CFD analysis tool for floating offshore wind turbines, Renewable Energy, 112(81): 280-301.

Loganathana, B; Gokhale, P; Kritpranama, T; Jitthanongsaka, P; FirozAlama, AD (2017). Investigate the feasibility of high aspect ratio vertical axis wind turbine, Energy Procedia, 110(19): 304 -309. 
Malachowski, Y (2006). Geographic Information System and Multi-Criteria

Papatheou, E; Dervilis, N; Maguire, AE; Campos, C; Antoniadou, I; Worden, K (2017). Performance monitoring of a wind turbine using extreme function theory, Renewable Energy, 113(3): 14901502.

Ribeiro, AED; Arouca, MC; Coelho, DM (2016). Electric energy generation from small-scale solar and wind power in Brazil, The influence of location, area, and shape. Renewable Energy, 85(8): 554-563.

Roberto-Parra, D (2014). Renewable energy research progress in Mexico: A review, Renewable and Sustainable Energy Reviews, 32(8): 140-153.

Safarian-Zangir, V; Zeinali, B (2017). Environmental Potentiometric of Renewable Wind Energy, Ardabil Province for Establishing a 5.2 MW Samen Turbine (AV928) Using the Software of GIS. Journal of Human and Environment. 16(5): 39-63

Sliz-Szkliniarza, B; Vogt, J (2011). GIS-based approach for the evaluation of wind energy potential. Renewable and Sustainable Energy Reviews, 15(5):1696-1707.

Smida, MB; Sakly, A (2015). Pitch Angle Control for Variable Speed Wind Turbines, J. Renewable Energy and Sustainable Development (RESD).
Smida, MB; Sakly, A (2016). Fuzzy Pitch Angle Control for Grid-Connected Variable-Speed Wind Turbine System, $7^{\text {th }}$ International Renewable Energy Congress (IREC).

Visacro, S; Silveira, FH (2015). Lightning Performance of Transmission Lines: Methodology to Design Grounding Electrodes to Ensure an Expected Outage Rate, Power Delivery, IEEE Transactions on, 30(12): 237-245.

Visacro, S; Silveira, FH; Alipio, R; De-Conti, A (2014). Lightning-Induced Voltages Over Lossy Ground: The Effect of Frequency Dependence of Electrical Parameters of Soil, Electromagnetic Compatibility, IEEE Transactions on, 56(6):11291136.

Wang, Y; Wu, Q; Gong, W; Peter, M; Gryning, S (2016). Hळ Robust Current Control for DFIG Based Wind Turbine Subject to Grid Voltage Distortions, IEEE Transactions on Sustainable Energy, 99(9): 137-162.

Zhongpeng, L; Feng, H; Shuowen, X; Xuesong, Z; Shilong, Z; Guorui, J; Haitao, D; Jian, F (2016). Individual Pitch Control of Wind Turbine Based on RBF Neural Network, Proceedings of the 35th Chinese Control Conference, PP: 27-29. 